\title{
The impact of efflux pumps on meropenem susceptibility among metallo- $\beta$-lactamase-producing and nonproducing Pseudomonas aeruginosa: Insights for better antimicrobial stewardship
}

\author{
Leandro Reus Rodrigues Perez PhD (1) \\ Hospital Mãe de Deus, Porto Alegre, Brazil
}

To the Editor-In the past several decades, carbapenemases have emerged as the main carbapenem-resistance mechanism in Pseudomonas aeruginosa, Acinetobacter spp, and more recently, among Enterobacterales. ${ }^{1}$ In Brazilian hospitals, $b l a_{\mathrm{SPM}-1}$ and $b l a_{\mathrm{IMP}-1}$ have been described as the most prevalent metallo- $\beta$ lactamase (MBL) genes among $P$. aeruginosa isolates. ${ }^{2}$ However, efflux pumps may contribute to carbapenem resistance development in $P$. aeruginosa because accumulation of the drug is reduced due to its rapid extrusion from the bacterial cell. ${ }^{3}$ Considering the lack of activity of carbapenem agents in front of these mechanisms, drugs such as ceftolozane/tazobactam (CT), have recently been targeted for new therapeutic approaches. Thus, it is crucially important to determine the exact mechanism that is occurring to establish a better stewardship strategy because CT does not have action on MBL-producing $P$. aeruginosa. ${ }^{4}$

In $P$. aeruginosa, efflux pumps have been categorized into 5 superfamilies, 4 of which belong to the resistance-nodulation division (RND) family: MexAB-OprM, MexCD-OprJ, MexEFOprN, and MexXY..$^{5}$ Efflux pump overexpression, particularly MexAB-OprM and MexXY, may cause high levels of carbapenem resistance among $P$. aeruginosa isolates. ${ }^{6}$ Although carbapenemases and efflux pumps have an important role in determining resistance, it is particularly difficult to infer the exact influence of each other because multiple resistance mechanisms may occur simultaneously.

The aim of this study was to evaluate the meropenem minimum inhibitory concentration (MIC) among meropenem-nonsusceptible $P$. aeruginosa, producing or non-producing MBLs, in the presence of a specific pump inhibitor agent, the L-phenyl-L-arginine $\beta$-naphthylamide $(\mathrm{Pa} \beta \mathrm{N}){ }^{7}$ Moreover, ceftolozane/tazobactam $(\mathrm{C} / \mathrm{T}) \mathrm{MICs}$ were determined for all isolates included in this study.

A set of 91 meropenem-nonsusceptible $P$. aeruginosa were consecutively included in this study. Only 1 isolate per patient was considered, which had been recovered from distinct clinical specimens (endotracheal aspirate, $\mathrm{n}=62$; sputum, $\mathrm{n}=10$; urine, $\mathrm{n}=10$; and others, $\mathrm{n}=9$ ) from hospitalized patients in southern Brazil from August 1, 2016, through February 2, 2017.

Meropenem MICs were determined by standard broth microdilution, according to the Clinical Laboratory Standards Institute (CLSI) protocol using P. aeruginosa ATCC 27853 and Escherichia

Author for correspondence: Leandro Reus Rodrigues Perez, PhD, Microbiology Unit, Hospital Mãe de Deus, 286, José de Alencar Street, 90610-000, Porto Alegre - RS, Brazil. Email: leandro.reus@gmail.com

Cite this article: Perez LRR. (2019). The impact of efflux pumps on meropenem susceptibility among metallo- $\beta$-lactamase-producing and nonproducing Pseudomonas aeruginosa: Insights for better antimicrobial stewardship. Infection Control \& Hospital Epidemiology, 40: 957-958, https://doi.org/10.1017/ice.2019.151 coli ATCC 25922 as strains for quality control. ${ }^{8} \mathrm{C} / \mathrm{T}$ MICs were determined by Etest (Liofilchem, Italy). For MBL gene detection, a real-time polymerase chain reaction (PCR) was performed as previously described. ${ }^{2}$ Broth microdilution using meropenem as substrate, ranging from 0.5 to $256 \mu \mathrm{g} / \mathrm{mL}$, in the presence of 50 $\mu \mathrm{g} / \mathrm{mL} \mathrm{Pa} \beta \mathrm{N}$, was performed to determine the MexAB-OprM overexpression activity, as described elsewhere. ${ }^{7}$ Efflux overexpression was determined when a decrease in meropenem MIC without inhibitor occurred at $\geq 2 \log 2 .{ }^{9}$ Isolates were evaluated in triplicate, and the results were visually screened after 24 hours of incubation at $35^{\circ} \mathrm{C}$.

Among our set of isolates, 15 (16.5\%) were MBL producers (13 $b l a_{\mathrm{SPM}-1}$ and $2 b{ } a_{\mathrm{IMP}})$, and among them, high levels of meropenem resistance (MICs $\geq 128.0 \mu \mathrm{g} / \mathrm{mL}$ ) were found. The remaining $76(83.5 \%)$ isolates were non-MBL producers with meropenem MICs ranging from 8.0 to $256.0 \mu \mathrm{g} / \mathrm{mL}$ (Table).

In the presence of $\mathrm{Pa} \beta \mathrm{N}$, all $P$. aeruginosa isolates showed a significant reduction in meropenem MICs, no matter the presence of any MBL gene (Table 1). Moreover, overexpression of the MexABOprM efflux pump was verified for all meropenem-resistant nonMBL-producing isolates. This result is in agreement with other studies, which have reported that $>70 \%$ of the isolates can overexpress efflux pump mechanisms like MexAB-OprM. ${ }^{3}$

This study highlights important issues: (1) the need to detect the exact carbapenem resistance mechanism involved (a simple phenotypic test such as blue-carba would be enough) because MBL producers are not elective for CT therapy; (2) better targeting of the use of new antimicrobials, such as CT, for those resistant isolates due to the overexpression of ampC enzyme associated with efflux pumps (ie, CT emerged as an important therapeutic agent with no resistance detected in this study and with low $\mathrm{MIC}_{50}$ and $\mathrm{MIC}_{90}$ of 1.0 and $2.0 \mu \mathrm{g} / \mathrm{mL}$, respectively [data not shown]); and (3) epidemiology survey of Pseudomonas resistance (currently, carbapenem-resistance due to efflux plus porin loss represent nearly $70 \%$ of all carbapenem-resistant Pseudomonas isolates) for rapid adjustment in stewardship programs to avoid antimicrobial resistance.

In conclusion, the presence of an efflux pump inhibitor $(\mathrm{Pa} \beta \mathrm{N})$ markedly decreases the level of meropenem resistance among $P$. aeruginosa isolates, ${ }^{10}$ regardless the presence of MBL, highlighting the role of efflux pump as an important mechanism to keep a high level of meropenem resistance. Additionally, microbiology labs should detect and report the presence of the resistance mechanism to establish the best antimicrobial use, particularly to prevent antimicrobial resistance development.

Author ORCIDs. Leandro Reus Rodrigues Perez, (D) 0000-0002-6662-6503

Acknowledgments. The author thanks Sophia Perez for technical support. 
Table 1. Effect of the Efflux Pump Inhibitor on Ceftolozane/Tazobactam and Meropenem MIC Values Among Meropenem-Nonsusceptible MBL-producing and Non-MBL-producing Pseudomonas aeruginosa

\begin{tabular}{|c|c|c|c|c|c|}
\hline \multirow[b]{2}{*}{ No. of Isolates } & \multirow[b]{2}{*}{ Efflux Pump } & \multirow[b]{2}{*}{ MBL Gene } & \multirow{2}{*}{$\begin{array}{c}\mathrm{C} / \mathrm{T} \mathrm{MIC}^{\mathrm{a}} \\
\text { Range, } \mu \mathrm{G} / \mathrm{ML}\end{array}$} & \multicolumn{2}{|c|}{$\begin{array}{l}\text { Meropenem MICb } \\
\text { Range, } \mu \mathrm{g} / \mathrm{mL}\end{array}$} \\
\hline & & & & Without $\mathrm{Pa} \beta \mathrm{N}$ & With $\mathrm{Pa} \beta \mathrm{N}$ \\
\hline 2 & MexAB-XY & $b l a_{\mathrm{IMP}}$ & $>256.0$ & $256.0-128.0$ & $2.0-8.0$ \\
\hline 12 & MexAB-XY & $b l a_{\mathrm{SPM}-1}$ & $>256.0$ & 256.0 & $4.0-8.0$ \\
\hline 1 & MexAB & $b l a_{\mathrm{SPM}-1}$ & $>256.0$ & 256.0 & 16.0 \\
\hline 10 & MexXY & None & $0.75-4.0$ & 256.0 & $8.0-16.0$ \\
\hline 8 & MexXY & None & $1.0-2.0$ & $8.0-64.0$ & 1.0 \\
\hline 6 & MexXY & None & 1.0 & 16.0 & $0.5-1.0$ \\
\hline 16 & MexXY & None & $1.0-2.0$ & $8.0-32.0$ & $0.5-1.0$ \\
\hline 12 & MexAB & None & $0.75-2.0$ & $16.0-32.0$ & 1.0 \\
\hline 10 & MexAB & None & 1.0 & 16.0 & $1.0-2.0$ \\
\hline 14 & MexAB & None & $1.0-4.0$ & $8.0-32.0$ & $1.0-2.0$ \\
\hline
\end{tabular}

Note. MBL, metallo- $\beta$-lactamase; MIC, minimum inhibitory concentration; Pa $\beta \mathrm{N}, \mathrm{L}$-phenyl-L-arginine $\beta$-naphthylamide. ${ }^{\mathrm{a}} \mathrm{C} / \mathrm{T}$ (ceftolozane/tazobactam) break points are $\leq 4 \mu \mathrm{g} / \mathrm{mL}$ (susceptible) and $>4 \mu \mathrm{g} / \mathrm{mL}$ (resistant).

${ }^{b}$ Meropenem break points are $\leq 4 \mu \mathrm{g} / \mathrm{mL}$ (susceptible) and $\geq 16 \mu \mathrm{g} / \mathrm{mL}$ (resistant).

Financial support. No financial support was provided relevant to this article.

Conflicts of interest. The author report no conflicts of interest relevant to this article.

\section{References}

1. Bush K, Jacoby GA. Updated functional classification of beta-lactamases. Antimicrob Agents Chemother 2010;54:969-976.

2. Perez LR, Antunes AL, Freitas AL, Barth AL. When the resistance gets clingy: Pseudomonas aeruginosa harboring metallo-beta-lactamase gene shows high ability to produce biofilm. Eur J Clin Microbiol Infect Dis 2012;31:711-714.

3. Cabot G, Ocampo-Sosa AA, Tubau F, Macia MD, Rodriguez C, Moya B, Zamorano L, Suarez C, Pena C, Martinez-Martinez L, Oliver A. Spanish network for research in infectious diseases (REIPI). Overexpression of AmpC and efflux pumps in pseudomonas aeruginosa isolates from bloodstream infections: prevalence and impact on resistance in a Spanish multicenter study. Antimicrob Agents Chemother 2011;55:1906-1911.

4. Livermore DM, Mushtaq S, Meunier D, Hopkins KL, Hill R, Adkin R, Chaudhry A, Pike R, Staves P, Woodford N, the BSAC Resistance
Surveillance Standing Committee. Activity of ceftolozane/tazobactam against surveillance and 'problem' enterobacteriaceae, pseudomonas aeruginosa and non-fermenters from the British Isles. J Antimicrob Chemother 2017;72:2278-2289.

5. Cattoir V. Efflux-mediated antibiotics resistance in bacteria. Pathol Biol 2004;52:607-616.

6. Poole K. Pseudomonas aeruginosa: resistance to the max. Front Microbiol 2011;2:65.

7. Lamers RP, Cavallari JF, Burrows LL. The efflux inhibitor phenylalaninearginine beta-naphthylamide $(\mathrm{PA} \beta \mathrm{N})$ permeabilizes the outer membrane of gram-negative bacteria. Plos One 2013;8:e60666.

8. Clinical and Laboratory Standards Institute (CLSI). Performance Standards for Antimicrobial Susceptibility Testing. Wayne, PA: CLSI; 2018.

9. Mesaros N, Glupczynski Y, Avrain L, Caceres NE, Tulkens PM, Van Bambeke F. A combined phenotypic and genotypic method for the detection of Mex efflux pumps in Pseudomonas aeruginosa. J Antimicrob Chemother 2007;59:378-386.

10. Lomovskaya O, Bostian KA. Practical applications and feasibility of efflux pump inhibitors in the clinic—a vision for applied use. Biochem Pharmacol 2006;71:910-918.

\title{
Forecasting from phenotypic testing to an antimicrobial stewardship strategy: Does the time to positivity of a blue-carba test predict the meropenem susceptibility level among carbapenemase producers?
}

\author{
Leandro Reus Rodrigues Perez PhD (1) \\ Hospital Mãe de Deus, Porto Alegre, Brazil
}

Author for correspondence: Leandro Reus Rodrigues Perez, PhD, Microbiology Unit, Hospital Mãe de Deus, 286, José de Alencar Street, 90610-000, Porto Alegre - RS, Brazil. Email: leandro.reus@gmail.com

Cite this article: Perez LRR. (2019). Forecasting from phenotypic testing to an antimicrobial stewardship strategy: Does the time to positivity of a blue-carba test predict the meropenem susceptibility level among carbapenemase producers? Infection Control \& Hospital Epidemiology, 40: 958-960, https://doi.org/10.1017/ice.2019.158
To the Editor-Currently, carbapenem-resistant Enterobacterales (CRE) have emerged worldwide at an alarming rate, causing both community and nosocomial infections. ${ }^{1}$ Carbapenem-resistance may be related to a decrease in bacterial outer-membrane 